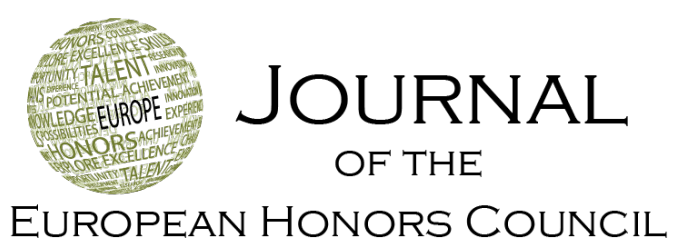

Note

\title{
Book Review of Robot-Proof: Higher Education in the Age of Artificial Intelligence
}

\author{
Author: Joseph E. Aoun \\ Publisher: Cambridge (MA), MIT Press \\ ISBN: 9780262535977 \\ Date: August 2018 \\ Paperback, 216 pages
}

Book Review by: Albert Pilot, emeritus professor at Utrecht University, email: A.Pilot@uu.nl

Received: 11 February 2020; Accepted: 22 May 2020; Published: 9 July 2020

Keywords: higher education; honors education; artificial intelligence

\section{Introduction}

The recent advances in artificial intelligence and the consequent exponential increase in the capacities of computers have led to the automation of many professional jobs. In his book Robot-Proof, Joseph Aoun, president of Northeastern University in Boston, proposes an approach to teaching the next generation of university students that not only fulfills the needs of society but that the most advanced artificial intelligence cannot fulfill. Aoun argues that robot-proof education should focus on a creative mindset and mental flexibility. He describes the framework for a new discipline, Humanics, which builds on the strong qualities of people and prepares students for a job market in which human professionals work closely with smart machines. Higher education based on Humanics can equip students for life and allow them to adjust to the world in constant flux, alongside the robots. Aoun's book has implications for education policy in universities around the world and, given its

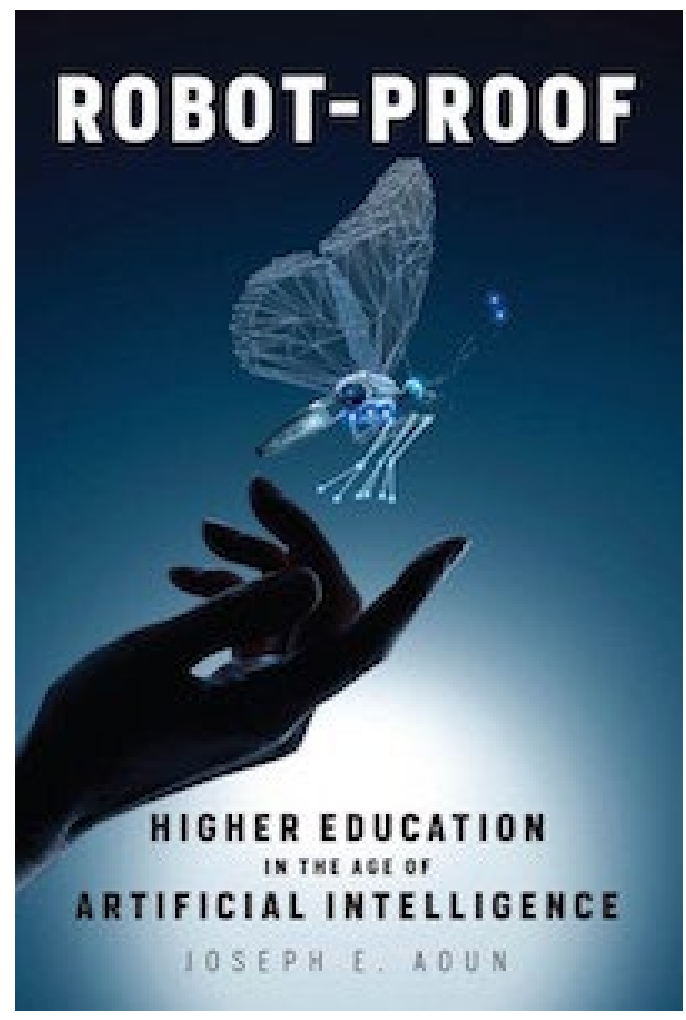
innovative nature in education, for honors programs as well. 


\section{Desired competencies that employers want}

The most requested new competencies by employers that Aoun reports include: the ability to work in multidisciplinary teams, good judgment, curiosity, empathy, leadership, a growth mindset, complex problem-solving, written communication, and abstract thinking skills that liberal arts education or honors programs develop rather than professional programs. The emphasis among employers has shifted from the knowledge of specific technical details of a discipline or field to holistic systems of thinking. Universities will thus play a key role in preparing their graduates for the future labor market that expects these competencies.

\section{New literacies and key cognitive capacities needed}

Aoun advocates three key literacies and four cognitive capacities as the core of the new robot-proof education that will enable the development of the key employer-desired competencies. He defines "Humanics" as a discipline that teaches both mastery of professional knowledge and the development of the new key literacies: technological literacy, data literacy, and human literacy. People need technological literacy to understand how machines work and how to use various tools to solve messy problems. Technological literacy requires knowledge of mathematics, coding, and basic engineering principles. Data literacy involves understanding and using "Big Data" through statistical analysis and context analysis to find meaning in a flood of information and present that meaning visually. Human literacy requires learning to interact with other people. Maintaining effective relationships is the key to a winning team; as is understanding people to help us address their problems and offer better products or services. Humanics thereby nurtures the students' mental and intellectual qualities that are unique to humans.

In addition to the three literacies, Aoun proposes four cognitive capacities as key for the future of university graduates. These capacities include critical thinking and systems thinking, the meta-skills to analyze, understand, and manage complex problems, as well as entrepreneurship and cultural agility, the ability to perform in cross-cultural settings. While some of the cognitive competencies named by Aoun can be found as critical outcomes in honors programs around the world, the literacies encompassed by Humanics typically are not as commonly addressed within honors and might be good candidates for future inclusion in honors programming.

\section{Teaching implications}

Aoun offers several ideas on how we as educators may teach to allow our students to stay relevant in the robotic-age while building context-dependent educational programs. He focuses on experiential learning models that allow students to experience concepts in concrete, authentic situations and process those experiences into relevant learning outcomes. To teach the new literacies and competencies, we need to expand our didactical toolbox. For example, thematic education across the boundaries of the disciplines, projectbased learning, and co-op education in which students alternate regular education in the classroom with long-term full-time immersion in professional practice and then integrate those two components are just a few examples of learning activities that can be created in the context of real-life situations. 
Aoun describes the stages in his proposed learning process as follows: 1) acquiring components of the skills; 2 ) practicing integrating the skill in a specific context, and 3) learning to apply the skill in new contexts. The concept of transfer and the distinction between 'near transfer' and 'far transfer' is of great importance in this regard (the latter being the most difficult), where the skills are applied in a distinctively new scenario. Both theoretical and practical knowledge are needed to successfully use experiences when applying skills in new contexts. Supervision by teachers is crucial for this learning process to facilitate far transfer. Since computers are not good at far transfer yet, far transfer skills will make students more robot-proof. According to Aoun, Humanics education with experiential learning as a catalyst is the most certain path to a robot-proof future.

\section{Lifelong learning (LLL)}

We no longer can assume that we are done learning when we graduate college. To stay relevant, learning must be a lifelong endeavor. Universities also might want to reconsider their concepts of a "student" and "alumnus." The existing universities are focused primarily on the standard forms of curricula for traditional students: the bachelor and master programs for students who come from secondary education and then forever leave their institutions as alumni after four to six years. Aoun argues in favor of breaking down this standard structure and re-thinking all the various aspects of the university. He proposes an educational model aimed at people who have a lot of time and little experience (the young alumni) and those who have little time and a lot of experience (the older alumni). Each group offers different opportunities to reconnect for further learning. Aoun also proposes that alumni should have a functional relationship with the universities, not just the usual social relationship, as alumni can be of great value in feeding their alma mater with new knowledge and experiences, creating new nodes of expertise for academic programs, research, educational resources, and opportunities for experiential learning.

The demand for LLL is now developing rapidly. In 2016, 40\% of students in colleges and universities in the US were older than what is traditionally considered a student. For 2025, the number of students older than 25 years is estimated at 9.7 million. Institutions must now capitalize on these new opportunities, offering a wide variety of programs aimed at different groups, becoming the hub of lifelong learning for everyone.

\section{Implications for universities and honors programs}

Aoun's book provides inspiring insights on how to adapt higher education to the developments in artificial intelligence with all the challenges, uncertainties, chance, and confusion surrounding it. The focus on the three literacies and four cognitive capacities give direction to the discussions regarding the future preparation of students for the changing labor market. From the perspective of lifelong learning, experiential learning, and examples of cooperation between institutions, course participants, and employers, Aoun shows what adjustments are needed in the educational policy of higher education institutions. I find the book highly relevant to European higher education, even though it is written in the US context. Honors programs can be a wonderful laboratory for the innovative education suggested by Aoun and a place for the needed professional development of future faculty. 